\title{
Integration of MFI Zeolite Membranes in the Light Gasoline Isomerisation Process
}

\author{
A. Baudot ${ }^{1}$ and L. Bournay ${ }^{2}$ \\ 1 Institut français du pétrole, IFP-Lyon, Direction Catalyse et Séparation, Rond-point de l'échangeur de Solaize, BP 3, 69390 Solaize - France \\ 2 Institut français du pétrole, IFP-Lyon, Direction Procédés, Rond-point de l'échangeur de Solaize, BP 3, 69390 Solaize - France \\ e-mail: arnaud.baudot@ifp.fr - laurent.bournay@ifp.fr
}

Résumé - Intégration de membranes zéolithes MFI dans le procédé d'isomérisation des essences légères - Des tests visant à augmenter l'indice d'octane d'un isomérat d'essence légère en extrayant du normal pentane au travers d'une membrane zéolithe de type MFI ont été réalisés. Les performances de séparation de la membrane ont été étudiées en fonction de la température et de la pression totale d'hydrocarbures en amont de la membrane. La densité de flux maximale de perméat, proche de $2 \mathrm{~kg} / \mathrm{m}^{2} . \mathrm{h}$, a été observée à $250^{\circ} \mathrm{C}-2$ bar de pression totale. Dans tous les cas, la concentration en normal pentane dans le perméat était trois fois supérieure à celle dans la charge. Une évaluation technicoéconomique complète de l'intégration de modules membranaires à base de zéolithe de type MFI sur une boucle d'isomérisation d'essences légères a été réalisée. Il a été montré que l'adjonction de membranes zéolithes de type MFI dans ce procédé n'est rentable que si le coût de revient des membranes installées est inférieur à $1000 € / \mathrm{m}^{2}$.

\begin{abstract}
Integration of MFI Zeolite Membranes in the Light Gasoline Isomerisation Process Tests aiming at separating normal pentane from a light gasoline isomerate through a MFI zeolite composite membrane were carried out. The performances of this membrane sample were studied as a function of total hydrocarbon pressure upstream of the membrane as well as the temperature. Maximal permeate flux, close to $2 \mathrm{~kg} / \mathrm{m}^{2} . h$, was observed at $250^{\circ} \mathrm{C}$ - 2 bar total hydrocarbon pressure. The normal pentane weight fraction was more than threefold higher in the permeate than in the feed. In a second step, a fully heat-integrated light gasoline isomerisation process loop integrating a MFI zeolite membrane-based separation was simulated and optimised. Integration of MFI zeolite membranes in this process proved to be valuable only if their cost is lower than $1000 € / \mathrm{m}^{2}$.
\end{abstract}




\section{INTRODUCTION}

For more than fifteen years now, regulations have imposed increasingly tight limitations on the content in gasoline of aromatic octane number boosters produced by the reforming of straight-run gasoline (alkanes). Amongst the available alternative technologies designed to enhance the octane number of straight-run gasoline, hydroisomerisation is a catalytic technology that upgrades low-octane-number linear paraffins into higher-octane-number branched paraffins, as illustrated in Table 1.

TABLE 1

Octane numbers of main components of a light gasoline

\begin{tabular}{c|c}
\hline Type of isomer & Research Octane Number (RON) \\
\hline Normal pentane & 61 \\
\hline Normal hexane & 31 \\
\hline Isopentane & 93.5 \\
\hline Methylpentanes & 75 \\
\hline Dimethylbutanes & $94-105$ \\
\hline Cyclohexane & 84 \\
\hline Benzene (reference) & 120 \\
\hline
\end{tabular}

Since the rate of conversion of linear paraffins in the isomerisation units is limited by a thermodynamic equilibrium, an option for increasing the production yield of dibranched paraffins consists of separating the linear and monobranched paraffins from the isomerisation unit effluent and recycling them in the input of the isomerisation reactor. The more conventional solution consists of fractionating the output stream from the isomerisation reactor through a continuous distillation column (a deisohexaniser or DIH), into three effluents:

- a sidestream, mainly containing unconverted normal hexane and the monobranched paraffins with 6 carbon atoms. This stream is recycled to the isomerisation unit;

- the bottom stream, containing the heaviest alkanes (paraffins) with 7 carbon atoms and naphthenes (cyclic paraffins) with 6 carbon atoms, with a RON of 82, is sent directly to the gasoline pool;

- at the top of the column, a head stream rich in dibranched paraffins with 6 carbon atoms, isopentane and normal pentane. This stream, which corresponds to $90 \%$ by weight of the fresh feed, has a RON (Research Octane Number) of 87 though it contains about $16 \%$ by weight of normal pentane, which has a low RON of 61.7 .

With current distillation processes, it is not economically feasible to separate normal pentane from the other components in the top stream of the deisohexaniser since, as shown in Table 2, the boiling points are very close.
TABLE 2

Boiling points (normal conditions) of main components in the head stream of a DIH

\begin{tabular}{c|c}
\hline Type of isomer & Boiling point $\left({ }^{\circ} \mathrm{C}\right)$ \\
\hline Isopentane & 27.9 \\
\hline Normal pentane & 36.1 \\
\hline Cyclopentane & 49.3 \\
\hline 2,2 dimethylbutane & 49.7 \\
\hline 2,3 dimethylbutane & 59.8 \\
\hline
\end{tabular}

This type of separation, however, can be achieved with molecular sieves, such as zeolites, implemented in cyclic adsorption processes such as a "simulated moving bed" (UOP MOLEX process) or "cycled pressurisation/depressurisation" (IFP IPSORB process or Exxon-Mobil ISOSIEVE process). With such processes, normal paraffins are preferentially adsorbed inside the micro-porosity of the zeolites and therefore separated from their branched isomers. Though offering excellent separation performance, this type of technology exhibits several drawbacks: high investment costs, sophisticated sequential operation (adsorption-desorption cycles), use of large quantities of solvents (desorbants) and lack of modularity.

Since the beginning of the 90s much attention has been paid to overcoming the drawbacks of conventional zeolite adsorbents through the development of zeolite membranes that combine the technical advantages of membranes (modularity, continuous operation) with the high separation performances of zeolites (due to their sieving properties). One of the most studied topics in this research field was the separation of normal short (C4-C6) paraffins from their branched isomers through MFI-type zeolite membranes [1-4]. Indeed, MFI zeolites are crystalline aluminosilicates with a microporous structure that is composed of two intricate micro-pore networks: elliptical straight channels with openings of $0.51 \mathrm{~nm} \times 0.55 \mathrm{~nm}$ and zigzag channels that are almost cylindrical with a diameter of $0.53 \mathrm{~nm} \times 0.56 \mathrm{~nm}$, as measured by X-ray diffraction at ambient temperature [1]. In such a confined porous system wherein the diameter of the micro-pores and the kinetic diameter of the diffusing molecules are close, the higher the kinetic diameter of a permeating molecule, the higher the friction of the molecule alongside the micro-pore wall, and therefore the lower its diffusion coefficient inside the micro-porosity of the MFI zeolite. Therefore, the diffusion coefficient of normal alkanes (which display a kinetic diameter of $0.43 \mathrm{~nm}$ [2]) in MFI zeolites is higher [3] than the diffusion coefficient of their monobranched isomers (with a kinetic diameter of $0.5 \mathrm{~nm}$ [4]). Moreover, these materials prove to be hardly permeable to dibranched paraffins (2,2 dimethylbutane displays a kinetic diameter of $0.63 \mathrm{~nm}$ [4]). It must be recalled here that, though the XRD micropore diameter is most often referred to as the main guideline 
for the sieving properties of a zeolite, this criterion should be addressed with care. Indeed, previous adsorption studies have shown that molecules displaying a larger kinetic diameter than the zeolite micro-pore diameters measured by XRD can somehow enter into MFI zeolite micro-porosity. Indeed, the 10-member oxygen rings constitutive of the micro-pores are not, strictly speaking, rigid and, for instance, naphthalene can distort the elliptical channels of H-ZSM-5 and enter the pores [4]. This phenomenon is favoured with increasing temperature.

The present paper's objective is to assess the performances of MFI zeolite membranes which appear to be particularly adequate for the separation of low-octane-number normal pentanes from the other branched paraffinic components contained in the head stream of a deisohexaniser. This document is composed of two main parts:

- experimental evaluation of the performances of a MFI zeolite membrane synthesised at IFP: a series of tests was carried out to separate mixtures of paraffins in the vapour phase containing $25 \%$ by weight of normal pentane (simulating a deisohexaniser top stream) on a laboratory scale on MFI-type zeolite membranes manufactured at IFP. The experiments were conducted, respectively, at a total hydrocarbon pressure upstream of the membrane of 2 and 4 bar at a temperature interval of between $150^{\circ} \mathrm{C}$ and $400^{\circ} \mathrm{C}$;

- technico-economic evaluation of the integration of MFI zeolite membranes in a conventional light gasoline isomerisation loop: based on the experimental performances of the studied MFI zeolite membranes, the opportunity to use MFI zeolite membranes in such a process is discussed on an economic basis.

\section{MATERIALS AND METHODS}

All the tests displayed in the present paper were conducted on a single MFI tubular membrane sample synthesised by IFP [5]. It is a composite membrane composed of a $20-\mu \mathrm{m}-$ thick MFI zeolite layer deposited inside the porosity of the lumen of an alpha-alumina porous tube. $15 \mathrm{~cm}$ long, it offers an "effective" area of $20 \mathrm{~cm}^{2}$.

The test campaign was divided into two steps:

- the first step consisted of characterising the membrane using pure compound permeation tests with the main molecules contained in a light gasoline through the membrane studied (under partial pressure in the feed and temperature similar to industrial conditions);

- the second step consisted of evaluating the "real" separation performance of the membrane by carrying out separation tests of mixtures (a "model" deisohexaniser top stream) under industrial conditions.

\subsection{Experimental Setup}

The partial pressure of the hydrocarbons in the vapour feed flowing at the upstream side of the membrane was regulated via the temperature monitoring of the saturator (Fig. 1). When the hydrocarbon partial pressure in the saturator was lower than or equal to atmospheric pressure, the organic vapours were swept to the membrane module by an inert vector gas (helium). All the tubing was heated at $150^{\circ} \mathrm{C}$ in order to prevent any condensation of the organic vapours. The vapour feed mixture flowed alongside the inner surface of the membrane tube (placed in heating shells) while the micrometric valve (V2 in Fig. 1) located at the outlet of the membrane module was used to regulate the pressure at the feed side of the membrane (upstream compartment).

The partial pressure of the compounds in the permeate was lowered by sweeping with helium $(5 \mathrm{~L} / \mathrm{h})$ in order to increase the driving force between both sides of the membrane and therefore favour permeation through the membrane. The permeate was then analysed with a gas phase chromatograph equipped with a gas injection loop and a Flame Ionisation Detector (FID). The permeate flow rate was measured with a Varian ADM 2000 volumetric flowmeter.

The retentate was collected at the membrane outlet in a condenser placed in dry ice. The flow rate of noncondensable gases was measured at the condenser outlet. Depending on the configuration studied, this effluent corresponded to the vector gas from the saturator and possibly to a fraction of sweep gas circulating in the permeate side and having diffused back through the membrane. This back-diffusion phenomenon was only observed when there was a helium partial pressure difference between the permeate and the retentate (tests with hydrocarbon feed of total pressure greater than 1 atmosphere). The condensed hydrocarbon mixture was then weighed and analysed by chromatography after the experiment.

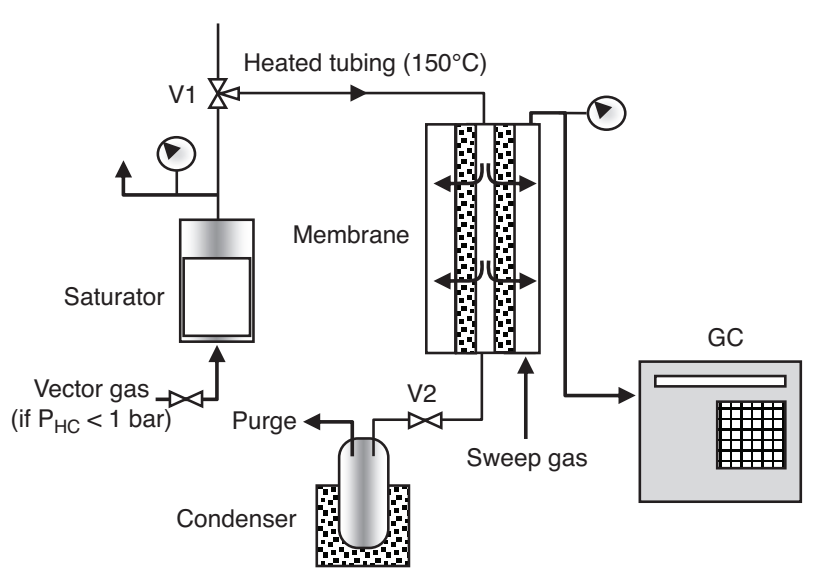

Figure 1

Vapour/gas permeation experimental setup. 


\subsection{Pure Compound Permeation Tests}

The pure compound permeation tests with the various paraffins were conducted under partial pressure in the feed and temperature conditions similar to the multicompound permeation tests.

Vapour permeation tests were carried out with normal pentane, isopentane and 2,2 dimethylbutane at various temperatures between $150^{\circ} \mathrm{C}$ and $300^{\circ} \mathrm{C}$ in steps of $50^{\circ} \mathrm{C}$; two partial pressures in isopentane, normal pentane and 2,2 dimethylbutane were tested at all these temperatures: respectively, 1 and 2 bar for isopentane, and 0.5 and 1 bar for normal pentane and 2,2 dimethylbutane.

\subsection{Multi-Component Permeation Tests}

The feed brought into contact with the membrane was obtained by vaporisation of a liquid mixture contained in a temperature-monitored saturator. The vapour feed corresponds to a simplified model version of the totally vaporised deisohexaniser top stream (Tab. 3). The composition of the liquid feed in the vaporisation was determined using Pro II software (Peng-Robinson model) according to the operating conditions required at membrane input (composition of the vapour feed, total pressure).

Vapour permeation tests were carried out at two total pressures ( 2 bar and 4 bar) and six temperatures (from $150^{\circ} \mathrm{C}$ to $400^{\circ} \mathrm{C}$ in steps of $50^{\circ} \mathrm{C}$ ).

\section{TABLE 3}

Mass fraction of main components of real feed of DIH top and of model feed

(in vapour state in contact with the upstream side of the membrane)

$\left.\begin{array}{l|c|c}\hline & \begin{array}{c}\text { Real DIH } \\
\text { top stream (w/w) }\end{array} & \begin{array}{c}\text { Model } \\
\text { vapour feed (w/w) }\end{array} \\
\hline \text { Isopentane } & \left.\begin{array}{r}46 \% \\
\text { 2-methylpentane }\end{array}\right\} & 53 \% \\
\hline \text { Normal pentane } & \begin{array}{c}20.6 \% \\
\text { Cyclopentane }\end{array} \\
\hline \text { 2,2 dimethylbutane } & 1.4 \% \\
\text { 2,3 dimethylbutane } & 5.6 \%\end{array}\right\}$\begin{tabular}{c}
$\longrightarrow$ \\
\hline
\end{tabular}

\section{EXPERIMENTAL RESULTS}

\subsection{Results of the Pure Compound Permeation Tests}

The results of the pure compound permeation tests are shown in the following figures (Fig. 2). The apparent 2,2 dimethylbutane flux was extremely low and could not be
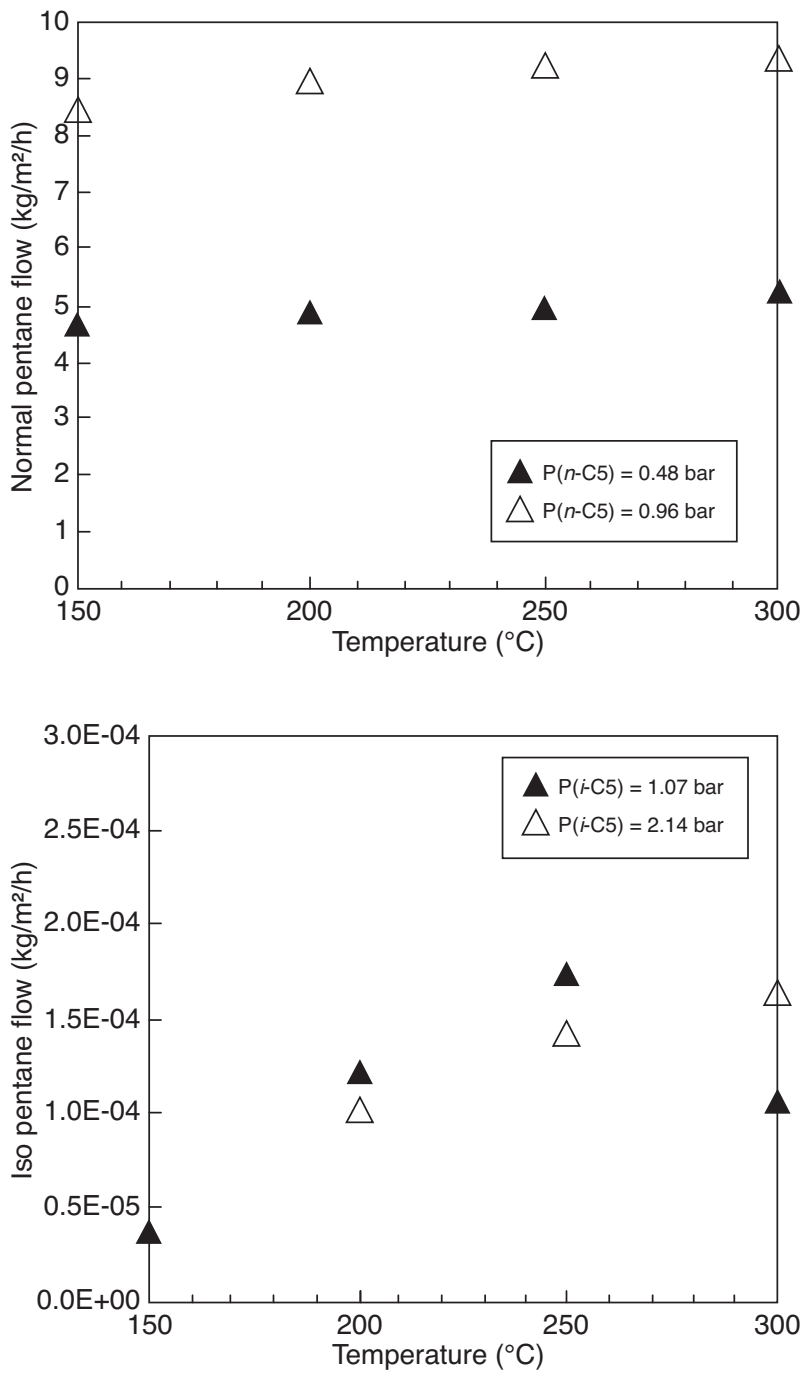

Figure 2

Pure compound permeation tests: graphs of normal pentane ( $n$-C5) and isopentane ( $i$-C5) fluxes $v s$ operating conditions.

measured on a reliable basis over the tested range of operating conditions.

An increase in the flux of these hydrocarbons with temperature was observed, reflecting a conventional phenomenon of activated diffusion of these paraffins in MFI zeolite, very similar to what was previously observed for alkanes (paraffins) of comparable size, especially butanes [6] The molecular sieving properties of the zeolite layer are clearly illustrated in the previous figure: the flux of the linear compound was four orders of magnitude greater than that of the branched compound, whereas the driving force inducing the transfer of material across the membrane (namely, the partial pressure difference between both sides of the membrane) was half that of normal pentane. It appears clearly here that a higher kinetic diameter induces more friction 
of the diffusing molecule alongside the micro-pore walls, leading therefore on a macroscopic scale to a lower diffusion coefficient.

\subsection{Results of the Multi-Component Permeation Tests}

\subsubsection{Start-Up}

The fluxes of the various compounds flowing through the membrane as a function of the test duration and the various operating conditions are shown in Figure 3. The "zero" point on the $x$-axis corresponds to the first analysis, carried out systematically 5 minutes after the opening of the saturator.

Generally speaking, two trends concerning the evolution of fluxes were observed as a function of time depending on the temperature.

At temperatures equal to or lower than $250^{\circ} \mathrm{C}$ the paraffin isomer fluxes evolved similarly as a function of time:

- with a decrease in the fluxes of the two pentane isomers then stabilisation;
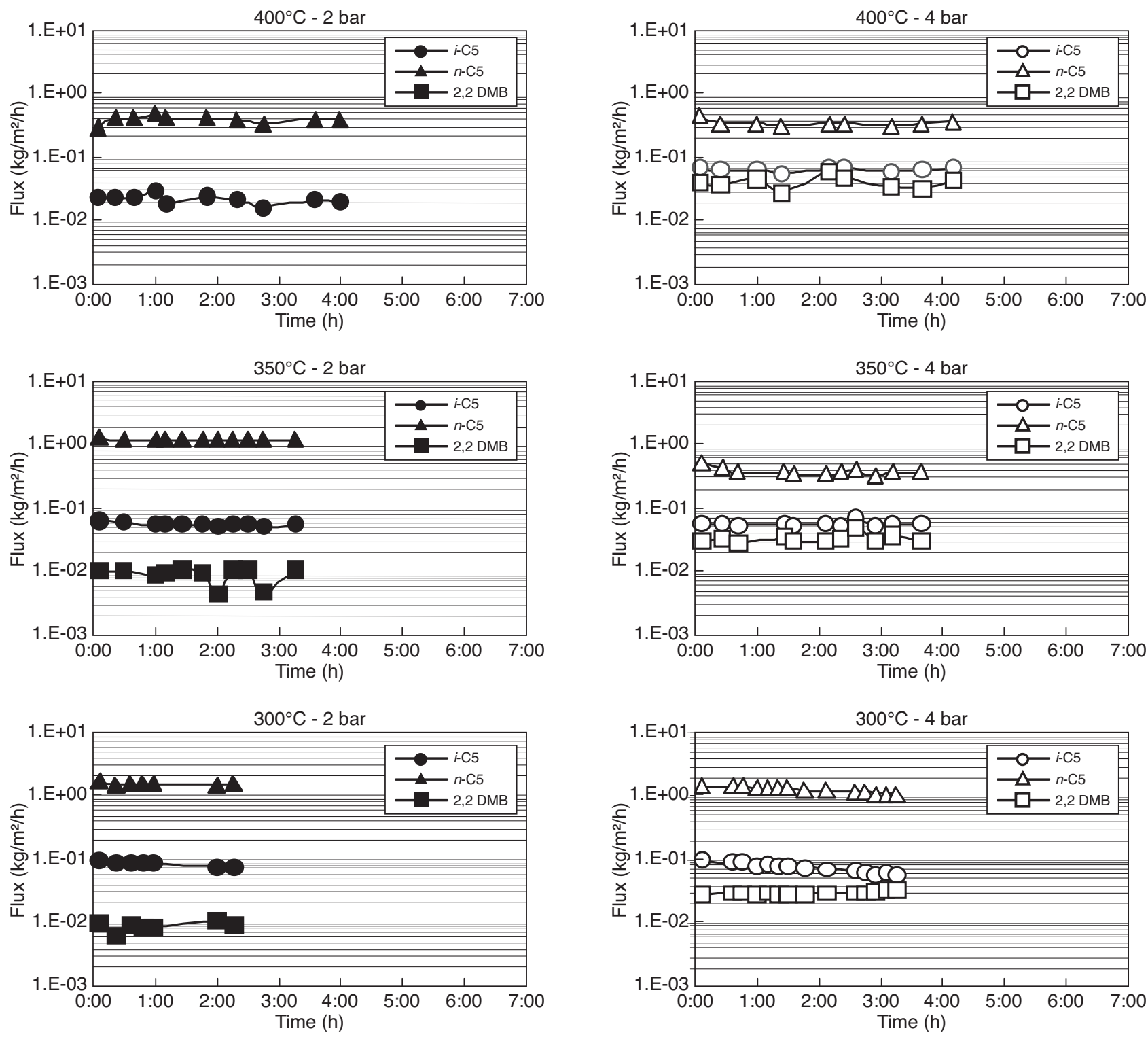

Figure 3a

Fluxes of normal pentane ( $n$-C5), isopentane (i-C5) and 2,2-dimethylbutane (2,2 DMB) against time at various "Total pressure/membrane temperature" pairs. 

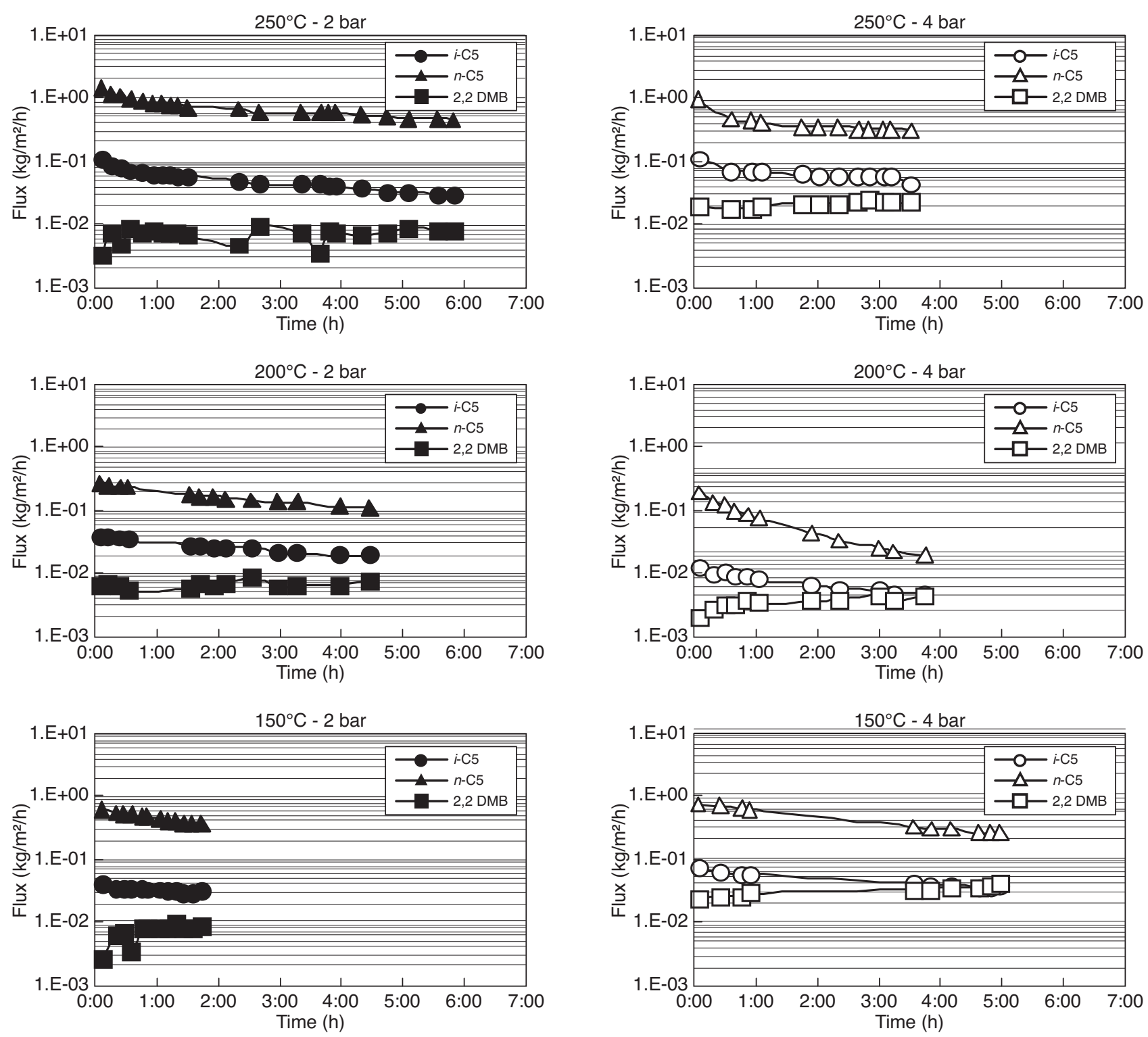

Figure $3 b$

Fluxes of normal pentane ( $n$-C5), isopentane (i-C5) and 2,2-dimethylbutane (2,2 DMB) against time at various "Total pressure/membrane temperature" pairs.

- associated with an increase in the flux of dimethylbutane then stabilisation.

These trends can be explained by the difference in diffusivity between the pentane isomers and dimethylbutane: at short times, only the pentanes (offering a smaller kinetic diameter than dimethylbutane and then probably diffusing faster in the micro-porosity) filled the empty micro-porosity of the MFI zeolite layer. Dimethylbutane entered the micro-porosity progressively, but much more slowly. This accounts for the slow increase in the dimethylbutane flux combined with a decrease in the fluxes of the lighter compounds induced by the adsorption (and possibly diffusion) competition. Indeed, it has been previously shown with homologous C6 paraffins (a mixture of normal hexane and 3-methylpentane) that increasing the concentration of the slowest paraffin (3-methylpentane) in the MFI zeolite micro-porosity led to a decrease in the apparent diffusion coefficient of the fast-diffusing paraffin (normal hexane) while the apparent diffusion coefficient of the "slow" mono-branched 3-methylpentane was raised [15]. The slowing of the fast-diffusing pentanes got more and more pronounced as time went on (resulting in a continuous decrease in their respective fluxes) as the micro-porosity was 
getting more and more filled with dimethylbutane, until the thermodynamic equilibrium was reached locally throughout the zeolite membrane thickness. Once the concentration profile had been established across the selective layer of the membrane, the fluxes stabilised (steady state). Matsufuji et al. [7] observed a similar trend in the fluxes of normal hexane and 2,3 dimethylbutane during pervaporation experiments at $30^{\circ} \mathrm{C}$ across a MFI membrane synthesised on a porous aluminium tube supplied by the NGK company. Similarly, Coronas et al. [8] also observed at the start of the test a reduction in the flux of hexane over time during permeation experiments using a 50/50 vapour mixture of $n$-hexane and 2,2 dimethylbutane butane at 0.05 bar partial pressure and $200^{\circ} \mathrm{C}$. This reduction in the hexane flux was nevertheless associated with a decrease in the dimethylbutane flux. At a later stage (after more than 20 hours), the fluxes of $n$-C6 and dimethylbutane decrease without ever stabilising (possibly due to a progressive coking of the zeolite micro-pores with time).

In contrast, at higher temperatures $\left(T>250^{\circ} \mathrm{C}\right)$, steady state was reached almost immediately. This is probably due to the fact that, due to the low covering rate of all the species inside the micro-porosity of the zeolite at these high temperature values, few interactions between the different permeating species were likely to occur, resulting in the absence of diffusion competition between the species.

\subsubsection{Steady-State Membrane Performances}

Conventionally, the performance of a membrane process is evaluated in terms of separation quality (selectivity) and productivity (flux).
This study focuses on the performance of the MFI membrane in "quasi-steady" state. The term "quasi" is used on purpose for the following two reasons:

- though the partial fluxes of hydrocarbons appear to be stabilised at the end of the tests between $250^{\circ} \mathrm{C}$ and $400^{\circ} \mathrm{C}$, this is not the case at lower temperatures. We nevertheless decided to include in the discussion the latest experimental values obtained during tests at $200^{\circ} \mathrm{C}$ (assuming that they were close to their asymptotes). Conversely, it appears that the values obtained at $150^{\circ} \mathrm{C}$ are not very reliable. Although the decrease in pentane fluxes with time seems less marked at $150^{\circ} \mathrm{C}$ than at $200^{\circ} \mathrm{C}$, this trend must be attributed above all to very slow diffusion kinetics and not to having reached the stabilised flux plateau;

- the stabilised fluxes were obtained over an extremely short period compared with the operating time of a unit running under industrial conditions. Since our installation was not designed to operate overnight, we were unable to check the stability of the membrane performance over a long period of time.

Since the mixture studied consists of more than two compounds, we were unable to calculate a separation factor, which is only applicable to binary mixtures. However, it was possible to compare "qualitatively" the composition of the permeate with that of the feed entering the membrane module (Fig. 4).

Generally speaking, irrespective of the operating conditions, the membrane always produced a permeate containing more than $70 \%$ weight fraction of normal pentane from a mixture containing less than $25 \%$ of this compound.
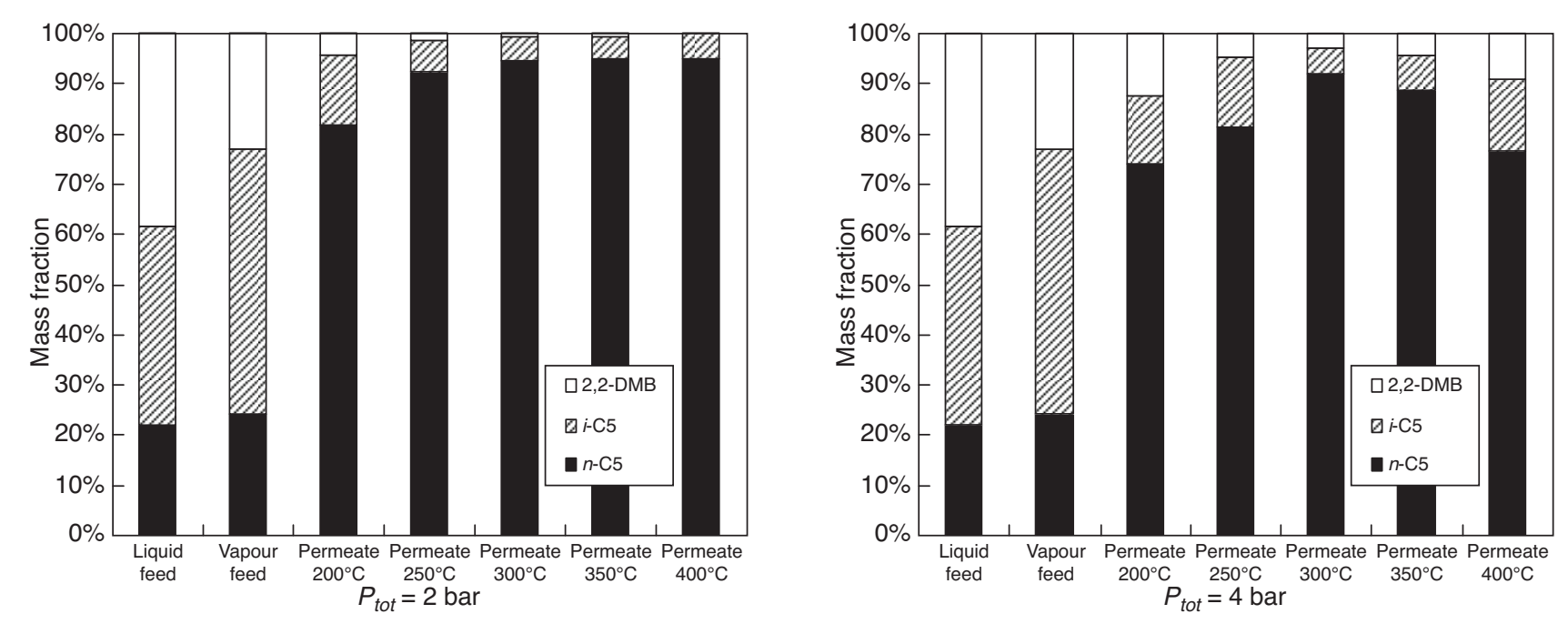

Figure 4

Relative composition (mass fraction) of the feed and permeate at quasi-steady state in the operating range studied. 

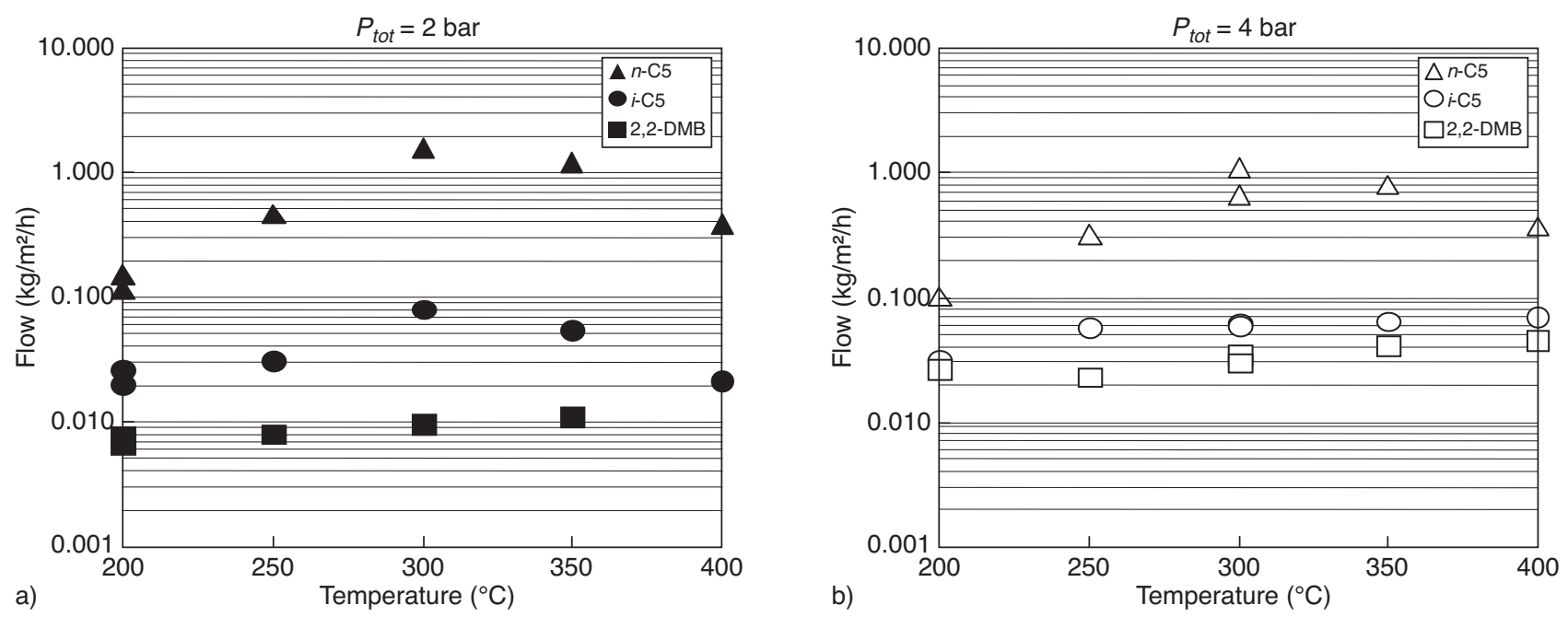

Figure 5

Multi-component permeation tests: fluxes of the various compounds across the membrane as a function of temperature and total pressure.

For a total pressure of 2 bar, enrichment of the permeate in $n$-pentane increases with temperature. This trend, already observed during previous vapour permeation tests conducted on $n$-hexane/2-methypentane binary mixtures, can be explained by several additive mechanisms [9]:

- the respective diffusion coefficients of $n$-pentane and branched compounds present in the feed have different activation energies. In other words, the diffusivities of the linear compounds would seem to increase faster with temperature than those of the branched compounds. Several authors have already observed this trend, on both $\mathrm{C} 4$ and C6 paraffin cuts [10, 11];

- the phenomenon whereby the fast compounds are slowed by the slowest compounds only occurs if the coverage rates (ratio of the local concentration of the adsorbed species in its zeolite over the concentration at saturation) of the branched compounds in the zeolite micro-porosity are high. This has been previously observed with a mixture of hexane/3-methylpentane isomers: the diffusion coefficient of the linear compound (normal hexane) in silicalite (a MFI zeolite containing only silica) was equal to $4.5 \times 10^{-11} \mathrm{~m}^{2} / \mathrm{s}$ when 3-methylpentane was absent from the micro-pores, whereas it was lowered to $10^{-11} \mathrm{~m}^{2} / \mathrm{s}$ when $83 \%$ of the micro-pore volume was filled with 3-methylpentane [12]. As the adsorption of branched paraffin isomers in MFI zeolite was decreasing with increasing temperature [13], the diffusion selectivity between the linear (faster) compounds and the branched compounds would therefore be more favoured at high temperatures.

Unlike the situation observed at 2 bar, the concentration of 2,2 dimethylbutane in the permeate increased at 4 bar for temperatures above $300^{\circ} \mathrm{C}$; it is possible that the transfer of dimethylbutane across the zeolite pores was favoured by higher adsorption of this compound in the zeolite due to its greater "flexibility" at high temperatures.

It therefore seems more interesting to operate the membrane in industrial conditions at relatively low hydrocarbon pressures, i.e. 2 bar total pressure, or even less, in order to achieve the best separation between the linear normal pentane from the other branched isomers contained in the feed.

Despite the excellent separation quality achieved with the membrane studied, the fluxes of the compound "to be extracted" (in our case $n$-pentane) remain rather low compared with the values required for separation on an industrial scale, currently between a few $\mathrm{kg} / \mathrm{m}^{2} \cdot \mathrm{h}^{-1}$ and several dozen $\mathrm{kg} / \mathrm{m}^{2} \cdot \mathrm{h}^{-1}$. Although the following examples are not directly related to our application, we may mention the performance of the only two micro-porous ceramic membranes currently on the market (designed for dehydration of solvents): ECN silica membranes (produced by Sulzer) and Mitsui NaA zeolite membranes can reach fluxes in water of about $10 \mathrm{~kg} / \mathrm{m}^{2} . \mathrm{h}$ (with a liquid feed at $120^{\circ} \mathrm{C}$ composed of $96 \%(w / w)$ ethanol and $4 \%\left(\mathrm{w} / \mathrm{w}\right.$ ) water) [14] and close to $5 \mathrm{~kg} / \mathrm{m}^{2}$.h (with a vapour feed at $105^{\circ} \mathrm{C}$ composed of $90 \%(\mathrm{w} / \mathrm{w})$ ethanol and $10 \%(\mathrm{w} / \mathrm{w})$ water) [15], respectively.

The graphs of fluxes in quasi-steady state of the various compounds forming the mixture studied are shown in Figure 5.

For the C5 compounds, the fluxes follow a bell-shaped curve, quite similar to that observed with butanes [5] but shifted towards higher temperatures. In contrast, we observed a steady increase in the flux of dimethylbutane with temperature, even for temperatures above $300^{\circ} \mathrm{C}$. Similar trends were observed with normal hexane/2,2 dimethylbutane mixtures permeating through $\mathrm{MFI} /$ alumina composite tubular membranes [4]. The bell-shaped curve of the normal paraffin flux 
vs temperature could be attributed to the competing effect of higher diffusivity with increasing temperature counterbalanced by a lowering of surface covering in the zeolite micropores, whereas it was assumed that dimethylbutane flux increase with increasing temperature could be attributed to transport through inter-crystalline defaults [4].

If we compare the pure compound and multicompound permeation results, under identical operating conditions (temperature and partial pressure upstream of the membrane) we observe a decrease of about one order of magnitude in the flux rate of normal pentane together with a significant increase in the flux of isopentane. The reduction in the flux of normal pentane in mixture is fairly logical: it can be explained by a decrease in the concentration of this compound at the upstream side of the zeolite selective layer due to competition with the other compounds present in the retentate, as well as by a reduction in its diffusivity due to the presence of much "slower" compounds blocking the porosity (especially dimethylbutane). In contrast, the isopentane seems to be entrained (accelerated) by the fastest compound (the flux of isopentane in mixture is about 100 times greater than that of the pure compound, although the driving force is the same). Such apparent acceleration of the slowest branched paraffin in the presence of the fastest linear paraffin has already been observed with a homologous linear/mono-branched paraffin isomer mixture though silicalite zeolites [15].

\section{TECHNICO-ECONOMIC EVALUATION OF THE INTEGRATION OF A MFI ZEOLITE-BASED MEMBRANE SEPARATION UNIT IN AN ISOMERISATION LOOP}

\subsection{Study Bases}

The technico-economic estimation calculations were carried out on a 2003 cost basis for a light gasoline isomerisation unit with a nominal capacity of 62 tonnes per hour, which represents an average processing capacity for this type of unit in Western refineries. The composition of the feed input to the isomerisation process is detailed in Table 4. It is representative of a typical light straight-run gasoline cut (obtained directly from atmospheric distillation). The Research Octane Number (RON) of this stream is equal to 68 .

The economic estimation consisted of evaluating two configurations:

- case 1: an isomerisation unit with deisohexaniser, which represents the base case (Fig. 6);

- case 2: the same isomerisation unit but with a zeolite membrane extraction unit installed on the top of the deisohexaniser. The normal pentane extracted in the permeate is recycled to the input of the isomerisation reactor (Fig. 7). According to case 2, two possibilities were studied. The first case consists of operating the membrane separation
TABLE 4

Composition of the isomerisation process feed used for the technico-economic evaluation

\begin{tabular}{l|c}
\hline Components & Mass fraction \\
\hline Isopentane & $14.4 \%$ \\
\hline Normal pentane & $30.6 \%$ \\
\hline 2,2-dimethylbutane +2,3-dimethylbutane & $1.7 \%$ \\
\hline 2-methylpentane + 3-methylpentane & $16.5 \%$ \\
\hline Normal hexane & $21 \%$ \\
\hline Other (including naphthenes) & $15.8 \%$ \\
\hline
\end{tabular}

unit at $300^{\circ} \mathrm{C}$ in order to obtain high fluxes and thereby reduce the membrane area required. There is nevertheless a drawback with these operating conditions: the feed must be vaporised with a furnace which consumes fuel gas. The second case consists of operating the membrane separation unit at $200^{\circ} \mathrm{C}$. Although impairing the membrane permeability, vaporisation of the feed can be achieved through a conventional steam-heat exchanger instead of a furnace, which leads to a significant reduction of the investment costs.

The financial benefit of integrating the membrane separation unit was evaluated by comparing:

- the additional expenses (investment costs and operating costs) induced by installing and operating the membrane separator;

- the gain related to the increase in the isomerate octane number induced by installing the membrane separator (the reference octane number being that of the isomerate obtained by case 1 without a membrane).

To quantify this gain in financial terms, two octane cost scenarios were considered:

- 3.1 euros per octane index point and per tonne of isomerate corresponding, in 2003, to an octane value considered as low;

- 5.0 euros per octane index point and per tonne of isomerate corresponding, in 2003, to a high octane value.

The material and enthalpy balances were generated from simulations carried out with PRO/II software (Simsci-Esscor, 26561 Rancho Parkway South, Lake Forest, CA). The following assumptions were used to calculate the membrane separation operation:

- rate of extraction of the normal pentane contained in the deisohexaniser top steam $=95 \%$;

- the monobranched isomers of hexane (2-methylpentane and 3-methylpentane) and the cyclopentane behave like isopentane;

- 2,3 dimethylbutane behaves like 2,2 dimethylbutane;

- the membrane area necessary to perform these operations is estimated using normal pentane flux values of $1 \mathrm{~kg} / \mathrm{h} / \mathrm{m}^{2}$ at $300^{\circ} \mathrm{C}$ and $0.1 \mathrm{~kg} / \mathrm{h} / \mathrm{m}^{2}$ at $200^{\circ} \mathrm{C}$. 


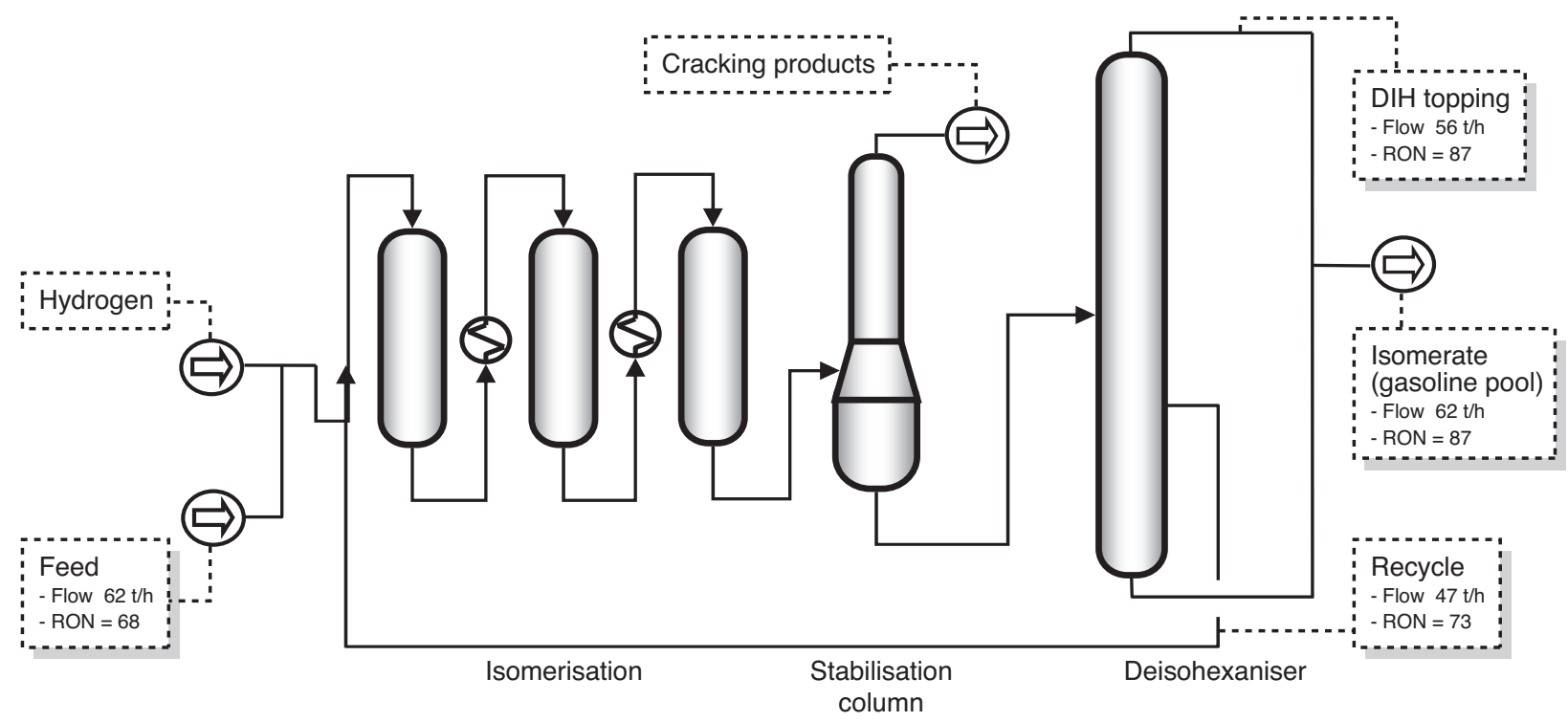

Figure 6

Base case of a light gasoline isomerisation unit equipped with deisohexaniser-based post-fractionation (process scheme type \#1 - reference case).

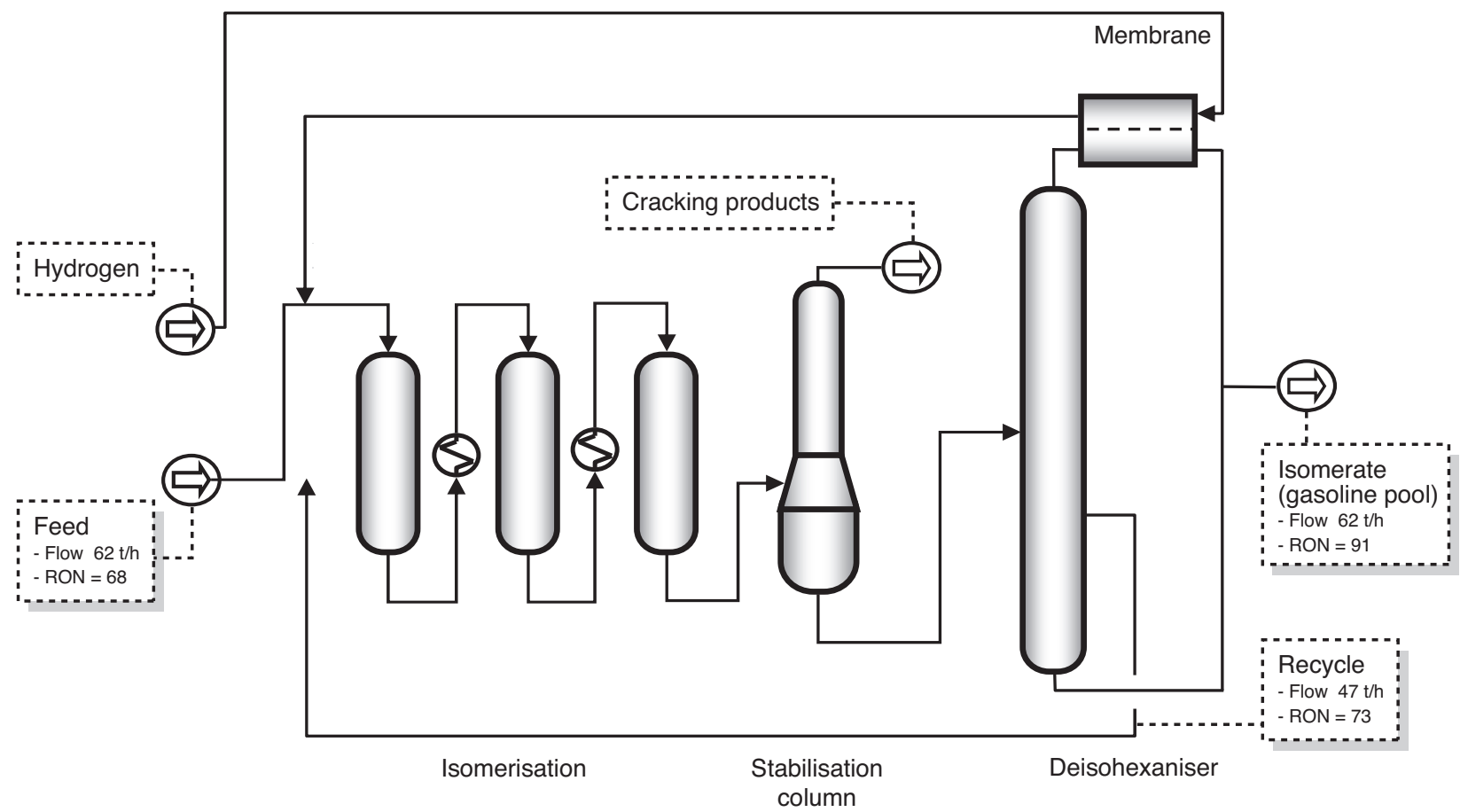

Figure 7

Diagram of a light gasoline isomerisation unit equipped with deisohexaniser- and membrane-based post-fractionation (process scheme \# 2 study case).

\subsection{Results}

The following parameters were estimated for each case:

- the limiting battery investment including the cost of equipment installed $+10 \%$ provisions for miscellaneous expenses not described;
- the operating costs including the costs of utilities, consumption of chemical products, cost of raw materials and cost of labour;

- the transformation cost per tonne of product based on a 10-year amortisation of the amortisable capital (Investments 
+ Utilities and storage + Engineering + Spare parts + Licence costs + Provisions for amortisation + Financial costs + Maintenance + Taxes and insurance + Overheads and management fees);

- for cases with a permeator, the gain in euros per tonne calculated on the basis of an octane cost of 3.1 and 5.0 euros per point and per tonne produced.

Since the MFI-type zeolite membranes were not produced industrially, the cost price for this type of material is not available. To obtain a homogeneous comparison basis for all configurations studied, we decided to use the investment cost of the membrane module as a parameter to balance the gain induced by installing the module with the additional cost of conversion related to operating this module (additional energy consumption related to vaporising the feed at the input of the membrane separation unit, additional hydrogen consumption in the reactor and amortisation of the invest- ment cost). This method allows us to estimate the break-even value expressed in price per $\mathrm{m}^{2}$ of membrane installed.

The results of the technico-economic analysis are listed in Table 5 (octane number at $3.1 € /$ octane number point/t) and Table 6 (octane number at $5 € /$ octane number point $/ \mathrm{t}$ ).

On a technical basis only, inserting a MFI zeolite-based separation unit significantly improves the performance of the isomerisation unit, increasing the octane number of the isomerate by more than three points. However, this substantial gain in terms of performance is offset by a significant increase in the isomerisation unit operating cost. This additional cost is mainly due to the energy consumption required to vaporise the feed input to the membrane separation unit and to the additional hydrogen consumption in the isomerisation reactor induced by the greater flow of feed to be processed related to recycling the normal pentane extracted at the top of the deisohexaniser. In all cases, if the cost of the

TABLE 5

Costs and gains of the light gasoline isomerisation process cases studied (octane number price $=3.1 € /$ RON point/t)

\begin{tabular}{|c|c|c|c|}
\hline & Process scheme \# 1 & $\begin{array}{l}\text { Process scheme \# } 2 \\
\left(T_{\text {membrane }}=300^{\circ} \mathrm{C}\right)\end{array}$ & $\begin{array}{l}\text { Process scheme \# } 2 \\
\left(T_{\text {membrane }}=200^{\circ} \mathrm{C}\right)\end{array}$ \\
\hline Limiting battery investment in $\mathrm{M} €$ & 19.45 & 23.23 & 24.78 \\
\hline Operating costs in $\mathrm{M} € /$ year & 8.43 & 13.05 & 11.80 \\
\hline Transformation cost in $€ / \mathrm{t}$ & 33.17 & 45.58 & 46.92 \\
\hline RON of the isomerate at process output & 87.0 & 90.5 & 90.5 \\
\hline Cost difference in $€ / t$ (compared with configuration 1) & - & 12.41 & 10.81 \\
\hline Gain in $€ / t$ (compared with configuration 1 ) & - & 10.93 & 10.81 \\
\hline Permissible price of the installed membrane module to reach break-even in $\mathrm{M} €$ & - & $\begin{array}{c}\text { Break-even } \\
\text { not reached* }\end{array}$ & 1.88 \\
\hline Membrane area to be implemented in $\mathrm{m}^{2}$ & - & 7500 & $\begin{array}{c}\text { Area }>10000 \mathrm{~m}^{2} \\
\text { (unrealistic scenario) }\end{array}$ \\
\hline
\end{tabular}

* The gain induced by the membrane module does not make up for the additional cost of conversion due to its operation.

TABLE 6

Costs and gains of the light gasoline isomerisation process cases studied (octane number price $=5 € / \mathrm{RON}$ point $/ \mathrm{t}$ )

\begin{tabular}{|c|c|c|c|}
\hline & Process scheme \# 1 & $\begin{array}{l}\text { Process scheme \# } 2 \\
\left(T_{\text {membrane }}=300^{\circ} \mathrm{C}\right)\end{array}$ & $\begin{array}{l}\text { Process scheme \# } 2 \\
\left(T_{\text {membrane }}=200^{\circ} \mathrm{C}\right)\end{array}$ \\
\hline Limiting battery investment in $\mathrm{M} €$ & 19.45 & 31.07 & 34.68 \\
\hline Operating costs in $\mathrm{M} € /$ year & 8.43 & 13.05 & 11.80 \\
\hline Transformation cost in $€ / \mathrm{t}$ & 33.17 & 50.92 & 50.73 \\
\hline RON of the isomerate at process output & 87.0 & 90.5 & 90.5 \\
\hline Cost difference in $€ / t$ (compared with configuration 1 ) & - & 17.75 & 17.56 \\
\hline Gain in $€ / t$ (compared with configuration 1$)$ & - & 17.75 & 17.56 \\
\hline Permissible price of the installed membrane module to reach break-even in $\mathrm{M} €$ & - & 7.1 & 10.9 \\
\hline Membrane area to be implemented in $\mathrm{m}^{2}$ & - & 7500 & $\begin{array}{c}\text { Area }>10000 \mathrm{~m}^{2} \\
\text { (unrealistic scenario) }\end{array}$ \\
\hline
\end{tabular}


octane number is low ( $3.1 € /$ point/t), addition of a MFI zeolitebased membrane separation unit is not financially justified (Tab. 6). Under these conditions, in fact, either the energy consumption related to vaporising the feed weighs too heavily on the operating costs (membrane temperature $300^{\circ} \mathrm{C}$ ), or the margin cleared by the gain in octane number is not sufficient to make construction of the membrane separation unit profitable, since it is too large. If the cost of the octane number is higher, addition of a membrane separation unit can only be justified if the zeolite membrane permeability is high, i.e. at $300^{\circ} \mathrm{C}$. In this case, the cost price of the membrane separation unit must be less than $1000 € / \mathrm{m}^{2}$ installed to justify the investment in this type of installation. According to the analyses conducted at IFP, this value currently represents a limit which is difficult to reach, considering the cost of the materials required to produce zeolite membranes and the cost of the membrane modules. However, significant progress can be expected in the following directions:

- reduction in the cost of porous inorganic supports;

- reduction in the thickness of the zeolite layer by one order of magnitude, to significantly reduce the membrane area required to extract a given flow rate.

Referring to the second criterion, it has already been demonstrated that the thickness of the zeolite membrane could be reduced by approximately one order of magnitude without any defects with respect to the materials used in this study [16]. However, extrapolation of a very small-scale synthesis in plane geometry to tubular structures on much larger areas remains a major technological challenge.

\section{CONCLUSIONS AND PERSPECTIVES}

In conventional straight-run light gasoline hydroisomerisation units, the reaction step is followed by fractionation of the isomerate by distillation in a deisohexaniser. The top stream (consisting mainly of normal pentane, isopentane and dimethylbutane) and the bottom stream (mainly naphthenes) are sent directly to the gasoline pool while the sidestream, consisting mainly of normal hexane and methylpentane, is recycled to the isomerisation reactor. In some cases (isomerisation of light gasolines), the top stream of the deisohexaniser can contain up to $25 \%$ by weight of normal pentane, which has a low octane number (about 60). Selective extraction of this compound from the top stream of the deisohexaniser followed by recycling to the isomerisation reactor in order to increase the isopentane yield of the isomerisation loop could produce a significant increase in the average octane number of the isomerate produced.

Tests were carried out on a laboratory scale to separate mixtures of paraffins in the vapour phase containing $25 \%$ by weight of normal pentane (simulating a deisohexaniser top stream to fractionate a light gasoline isomerisation reactor effluent) on MFI-type zeolite membranes manufactured at
IFP. The experiments were conducted under industrial conditions (respectively, at a total hydrocarbon pressure upstream of the membrane of 2 bar and 4 bar at a temperature interval of between $150^{\circ} \mathrm{C}$ and $400^{\circ} \mathrm{C}$ ). The maximum flux of permeate was observed at $250^{\circ} \mathrm{C}-2$ bar total pressure and was close to $2 \mathrm{~kg} / \mathrm{m}^{2}$.h. In contrast with what might be expected, it seems that increasing the total pressure reduces the transmembrane fluxes. Increasing the total hydrocarbon pressure at the upstream side of the membrane led apparently to an increased sorption of the slowest compounds (branched paraffins), which slowed down the diffusion of the fastest species (linear paraffins) across the selective zeolite layer. The MFI-type zeolite membrane tested nevertheless proved to be highly selective with respect to normal pentane, irrespective of the operating conditions studied. In all cases, in fact, the normal pentane concentration in the permeate was greater than $70 \%$ by weight.

On the basis of these results, a complete technico-economic evaluation (2003 reference costs) concerning the integration of membrane modules on a light gasoline isomerisation loop was conducted using SimSci Pro/II software. It appears that adding zeolite membranes in this type of process is only profitable if the price of the octane number is high $(>5 € / \mathrm{t})$. In this case, the price per $\mathrm{m}^{2}$ of zeolite membrane installed must be less than $1000 € / \mathrm{m}^{2}$ if the gains induced are to offset the additional costs related to installing and operating this type of technology. The reduced permeability of the membrane tested nevertheless appears to be its main limitation. In this study case, in fact, high transmembrane fluxes could only be achieved at the expense of increased energy consumption, related to the very high operating temperature in the membrane modules. Consequently, the main progress in membrane zeolite materials still lies in the ability to produce zeolite membranes with a much thinner selective layer.

\section{REFERENCES}

1 Flanigen E.M., Bennet J.M., Grose R.W., Cohen J.P., Patton R.L., Kirchner R.M. (1978) Silicalite, a new hydrophobic crystalline silica molecular sieve, Nature 271, 512-516.

2 Sommer S., Melin T., Falconer J.L., Noble R.D. (2004) Transport of C6 isomers through ZSM-5 zeolite membranes, $J$ Membrane Sci. 224, 51-67.

3 Courthial L., Baudot A., Tayakout-Fayolle M., Jallut C. (2008) A transient permeation-based method for composite zeolite membrane characterisation, AIChE J. 54, 2527-2538.

4 van Koningsveld H., Jansen J.C. (1996) Single Crystal structure analysis of zeolite H-ZSM-5 loaded with naphtalene, Micropor. Mesapor. Mat. 6, 159-167.

5 Sicard M. (2001) Synthèse et caractérisation de membranes zéolithiques supportées, Thèse, Université de Haute Alsace, Mulhouse, France.

6 Kapteijn F., Moulijn J.A., Stol A., Van der Bijl E., Van de Graaf J.M. (1998) Effect of Operating Conditions and Membrane Quality on the Separation Performance of composite silicalite 1 Membranes, Ind. Eng. Chem. Res. 37, 4071-4083. 
7 Matsufuji T., Watanabe K., Nishiyama N., Egashira Y., Matsukata M., Ueyama K. (2000) Permeation of Hexane Isomers through an MFI Membrane, Ind. Eng. Chem. Res. 39, 2434-2438.

8 Coronas J., Noble R.D., Falconer J.L. (1998) Separations of C4 and C6 Isomers in ZSM-5 Tubular Membranes, Ind. Eng. Chem. Res. 37, 166-176.

9 Baudot A. (2003) Permeation of C-6 Isomers through Ceramic Membranes, International Membrane Science and Technology Conference IMSTEC'03, Sydney, 10-14 November 2003.

10 Millot B. (1998) Étude du transport d'hydrocarbures saturés dans des membranes zéolithiques de structure MFI, Thèse, Université Claude-Bernard - Lyon I, France.

11 Zhu W., Kapteijn F., Moulijn J.A. (2001) Diffusion of Linear and Branched C6 Isomers in Silicalite-1 Studied by the TaperedElement Oscillating Microbalance, Micropor. Mesorpor. Mat. 47, 157-171.

12 Schuring D., Koriabkina A.O., de Jong A.M., Smit B., van Santen R.A. (2001) Adsorption and diffusion of n-hexane/2methylpentane mixtures in zeolite silicalite: experiments and modeling, J. Phys. Chem. B 105, 7690-7698.
13 Gardner T.Q., Lee J.B., Noble R.D., Falconer J.L. (2002) Adsorption and diffusion properties of butanes in ZSM-5 zeolite membranes, Ind. Eng. Chem. Res. 41, 4094-4105.

14 Van Veen H.M., Van Delft Y.C., Engelen C.W.R., Pex P.P.A.C. (2001) Dewatering of Organics by Pervaporation with Silica Membranes, Sep. Purif. Technol. 22-23, 361-366.

15 Morigami Y., Kondo M., Abe J., Kita H., Okamoto K. (2001) The First Large-scale Pervaporation Plant using Tubular-type Module with NaA Membrane, Sep. Purif. Technol. 25, 251-260.

16 Heldlund J., Sterte J., Anthonis M., Bons A.-J., Carstensen B., Corcoran N., Cox D., Deckman H., De Gijnst W., De Moor P.P., Lai F., Mchenry J., Mortier W., Reinso J., Peters J. (2002) High-Flux MFI Membranes, Micropor. Mesopor. Mat. 52, $179-189$
Final manuscript received in August 2009 Published online in November 2009 